\title{
Spontan Solunumu Olan Gönüllülerde Cerrahi Hasta Pozisyonlarının Plet Değişkenlik İndeksi , Perfüzyon İndeksi ve Noninvaziv Sürekli Kardiyak Output Ölçüm Yöntemi Üzerine Olan Etkisi
}

\section{The Effect of Surgical Patient Positions on Plet Variability Index, Perfusion Index and Noninvasive Continuous Cardiac Output Measurement Method in Voluntary Breathing Volunteers}

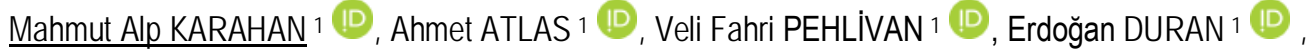 \\ Başak PEHLIVAN ${ }^{1}$ (D) , Melike ABAN YILMAZ ${ }^{1}$ (D) , Orhan BiNici 1 (D) , Nuray ALTAY 1
}

1 Harran Üniversitesi Tıp Fakültesi Anesteziyoloji ve Reanimasyon Anabilim Dalı Şanlıurfa, Türkiye

Öz.

Amaç: Cerrahi prosedür için verilen farklı pozisyonlar doku perfüzyonunda ve kardiyak outputta değişikliklere neden olabilir. Bu çalışmada spontan solunuma sahip katııımcılarda plet değişkenlik indeksinin (PVI), perfüzyon indeks (PI) ve noninvaziv sürekli kardiyak output ölçüm yöntemi (EscCO) nin farklı cerrahi pozisyonlardaki değişimlerini araştırmayı amaçladık.

Materyal ve Metod: 20 katııımıdan oluşan bir sağlıklı birey grubu prospektif gözlemsel çalışmaya dahil edildi. Sırasıyla Supin, 30 derece baş yukarı, 45 derece baş yukarı, 20 derece Trendelenburg, 20 derece tersTrendelenburg, ve pron pozisyonları uygulandı. Her pozisyon arası $10 \mathrm{ar} \mathrm{dk}$ olacak şekilde süre tutuldu. Her pozisyon değişikliğinden önce gönüllüler sırtüstü pozisyona alındı ve beş dakika dinlendikten sonra yeni pozisyon verildi. Pozisyon değişiminden sonraki 5. dakika PI, PVI, EscCO, SpO2 değerleri kayıt altına alındı.

Bulgular: Katılımcıların farklı pozisyondayken ölçülen PI, PVI ile EscCO değerlerinde istatistiksel olarak anlamlı bir fark bulunamadı.

Sonuç: Bu çalışma, PI, PVI ile EscCO nun tüm cerrahi pozisyonlarda herhangi bir değişikliğe uğramadığını ve her üç parametrenin de spontan solunumuna sahip genç sağlıkı bireylerde pozisyondan etkilenmediği ortaya koymuştur.

Anahtar Kelimeler: Kardiyak output, Cerrahi, Perfüzyon indeksi

\section{Abstract}

Background: Different positions given for the surgical procedure can cause changes in tissue perfusion and cardiac output. In this study, we aimed to investigate the changes of pleth variability index (PVI), perfusion index (PI) and noninvasive continuous cardiac output measurement method (EscCO) in different surgical positions in participants with spontaneous breathing.

Materials and Methods: A sample of 20 healthy individuals was included in the prospective observational this study. Participants held six different positions: supine, prone, 30 degrees upside, 45 degrees upside, trendelenburg (20-degrees head down), and reverse trendelenburg (20-degrees head up). The time was kept 10 minutes between each position. Before each position change, volunteers were placed in the supine position and after five minutes of rest, a new position was given. After the position change, PI, PVI, EscCO, peripheral capillary oxygen saturation values at $5^{\text {th }}$ minutes were recorded.

Results: No statistically significant difference was found in PI, PVI and EscCO values measured while the participants were in different positions ( $p>0.05)$.

Conclusion: This study revealed that PI, PVI and EscCO did not change in all surgical positions, and this parameters were not affected by position in young healthy individuals with spontaneous breathing.

Key words: Cardiac output, Surgery, Perfusion index
Sorumlu Yazar $I$

Corresponding Author

Dr. Mahmut Alp KARAHAN

Harran Üniversitesi Tıp Fakültesi Araştırma ve Uygulama Hastanesi B Blok Haliliye/Şanlıurfa

e-mail: mahmutalp_k@yahoo.com Tel: 04143444444 (4473)

Geliş tarihi / Received: 11.03.2020

Kabul tarihi / Accepted: 31.03 .2020

DOI: 10.35440/hutfd.691101 


\section{Giriş}

Cerrahi vakalar sırasında cerrahi alanın daha rahat görülebilmesi, cerrahi erişimi daha da kolaylaştırmak amacıyla cerrahın tercihine göre, pron, supin, oturma, litotomi, trendelenburg veya ters trendelenburg gibi hastaya çeşitli pozisyonlar verilmektedir. Farklı pozisyonlar hastanın kan basıncı, kalp atım hızında ve de otonom sinir sisteminde denge değişimi gibi farklı hemodinamik ve solunum değişiklikleri yol açabilmektedir. Uzun süren pozisyonlarda doku perfüzyonunu bozabilir (1). Bir hastanın sıvı resüsitasyonuna cevap verip vermeyeceğini belirlemek, intraoperatif dönemde en önemli, ancak sıklıkla zor görevlerden biridir çünkü cerrahi sırasında intravasküler hacmin yeterliliğinin kesin olarak değerlendirilmesi zordur. Ancak santral venöz basınç gibi statik indeksler, invaziv olarak ölçülmesine rağmen sıvı duyarlılığını tahmin etmede zayıf bir parametredir (2). Invaziv kateter riskinin potansiyel faydalarından daha ağır bastığı durumlarda kalp-akciğer etkileşimlerine dayanan, kolay uygulanabilirliği non-invaziv, sürekli ölçülebilen dinamik indeksler hastalarda sıvı duyarlıIIğını tahmin etmek için alternatif olabileceği gösterilmiştir (3).

Pleth değişkenlik indeksinin (PVI), Perfüzyon indeks (PI) ve noninvaziv sürekli kardiyak output ölçüm yöntemi (EscCO) son yıllarda güncel olarak kullanılan hastanın sıvı dengesi hakkında önbilgi veren noninvaziv monitörizasyon yöntemleridir $(2,4,5)$. Bu denge değişikliğini araştırmak için spontan solunumu olan sağlıkı bireylerde farkı pozisyonel değişikliklerin PVI, PI İle EscCO üzerindeki etkilerini değerlendirmeyi amaçladık.

\section{Materyal ve Metod}

Araştırmamız prospektif gözlemsel çalışma olup çalışmaya 18-80 yaşları arasında ASA I-II olan 20 sağlıklı gönüllüler dahil edildi. Çalışma anesteziyoloji ve reanimasyon anabilim dalında gerçekleştirildi. Çalışma Harran Üniversitesi klinik araştırmalar etik kurulu tarafından onaylandı (2020 yılı,05 oturum, 30 sayılı ). Tüm gönüllü katııımcılardan yazııı onam alındı. Her hangi bir Karaciğer ve/veya Böbrek yetmezliği olan, obez hastalar(BMI 30 ve üzeri), travma hastaları, kanser hastaları, ASA IV hastalar, acil cerrahi, kardiyak aritmi, implante kalp pili olanlar, kronik ağrı öyküsü olanlar çalışma dışı bırakıldı.

Yoğun bakım ünitesinde çeşitli açılarda posizyon vermeye uygun hasta yatağında gönüllülere EscCO uyumlu monitör kullanılarak (Nihon Kohden, Tokyo, Japan ) standart monitörizasyon olan Elektrokardiyografi (EKG) periferik oksijen satürasyonu (SpO2), noninvaziv kan basıncı (NIBP) uygulandı. Bazal sistolik arter basıncı (SAB) ve kalp atım hızı (KAH) kayıt edildi. Sağ işaret parmağına takılan prob kullanılarak PI ile PVI (Masimo Root; Masimo Corp., Irvine, CA, USA) ilk ölçüm yapıldı. Ardından EscCO uyumlu monitörden ilk değer alındı. Sırasıyla Supin, 30 derece baş yukarı, 45 derece baş yukarı, 20 derece Trendelenburg, 20 derece ters-Trendelenburg, ve pron pozisyonları uygulandı. Her posizyon arası 10 ar dk olacak şekilde süre tutuldu. Her pozisyon değişikliğinden önce gönüllüler sırtüstü pozisyona alındı ve beş dakika dinlendikten sonra yeni pozisyon verildi. Posizyon değişiminden sonraki 5. dakika PI, $\mathrm{PVI}$, EscCO, SpO2, KAH,SAB değerleri kayıt altına alındı. Her ölçüm aynı uzman tarafından yapıldı.

\section{İstatistiksel analiz}

İstatistiksel analiz SPSS sürüm 23.0 yazılımı (SPSS Inc., Chicago, IL, ABD) kullanılarak yapıldı. Betimsel istatistiklerde, normal dağılım Tek Numune Kolmogorov Smirnov testi ile belirlenir ve normal olarak dağıtılmayan sürekli değişkenler medyan (min-max), kategorik değişkenler sayı ve yüzde olarak ifade edildi. İkiden fazla grubun sürekli değişkenlerini karşılaştırmak için Kruskall Wallis testi kullanıldı. İki sürekli değişkenin korelasyonu Spearman Rho Korelasyonu ile hesaplandı; 0-0,3 arasındaki $r$ değeri zayıf, 0,3-0,7 orta ve 0,7-1 güçlü korelasyon olarak kabul edilmiştir. $P$ $<0,05$ değeri istatistiksel olarak anlamlı kabul edildi.

\section{Bulgular}

Çalışmamıza toplamda 8 kadın 12 erkek olmak üzere 20 gönüllü katılmıştır. Katılımcıların yaş ortalaması $26,95 \pm 4,34$ olup kilo ve boy ortalamaları sırasıyla $67,35 \pm$ 14,17 ve $170 \pm 9,14$ tür. Farklı vücut pozisyonlarındaki hemodinamik değişikliklerin karşılaştırıması Tablo 1 'de gösterilmiştir.

Tablo 1. Farklı vücut pozisyonlarındaki hemodinamik değişikliklerin karşılaştırıması

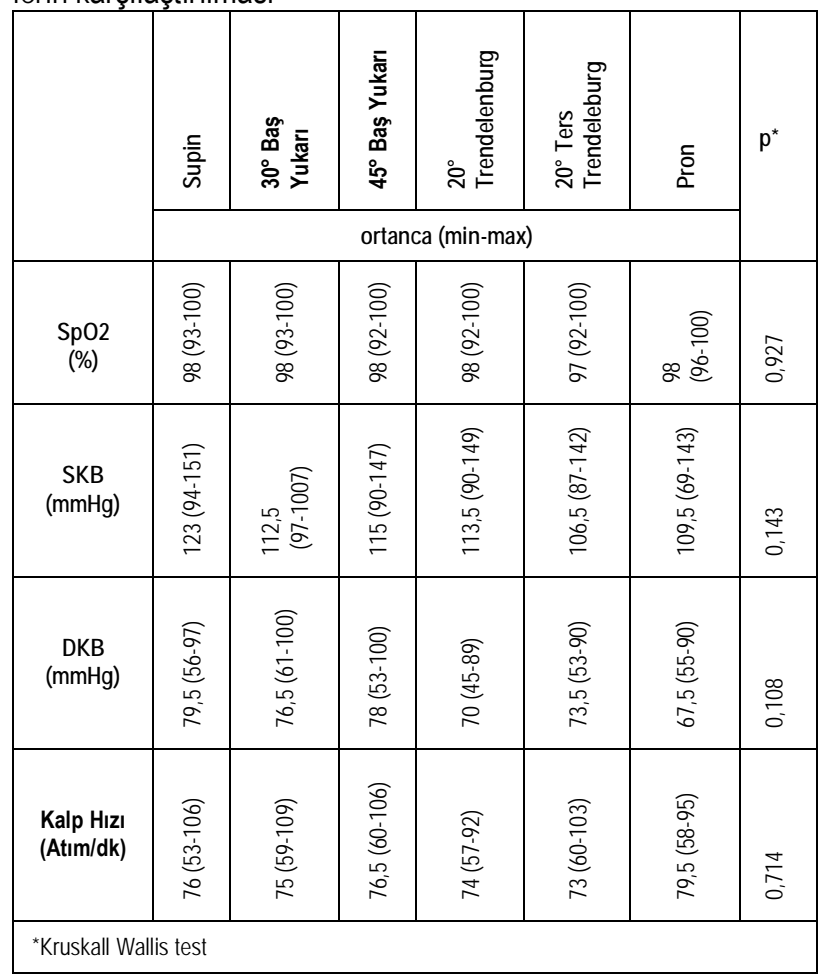

Demografik veriler ve vital bulgular tüm gruplarda benzerdi. PI, PVI ve EscCo değerleri tüm gruplarda benzerdi. Ayrıca alt grup analizleride anlamlılık ortaya koymamıştır. 
Tablo 2. Farklı pozisyondayken ölçülen PI, PVI ile EscCO değerlerinin karşı|lştıııması

PI $\quad$ PVI $\quad$ EscCO
Ortanca (min-max)

\begin{tabular}{|c|c|c|c|}
\hline \multicolumn{4}{|l|}{ Posizyon } \\
\hline Supin & $4,25(0,7-25)$ & $21,5(7-41)$ & $5,03(1,7-6,91)$ \\
\hline $30^{\circ}$ Baş Yukarı & $3,9(0,94-9,8)$ & $19,5(8-99)$ & $5,04(3,21-6,95)$ \\
\hline $45^{\circ}$ Baş Yukarı & $3,8(1-9,8)$ & $22,5(13-40)$ & $4,99(3,26-7,16)$ \\
\hline $\begin{array}{l}20^{\circ} \\
\text { Trendelenburg }\end{array}$ & $4,55(1,2-13)$ & $20(10-38)$ & $5,05(1,92-6,22)$ \\
\hline $\begin{array}{l}20^{\circ} \text { Ters } \\
\text { Trendelenburg }\end{array}$ & $3,55(1,1-9,6)$ & 19,5 (11-34) & $4,92(1,19-6,3)$ \\
\hline Pron & $2,95(0,98-8)$ & $19(11-34)$ & $5,34(1,8-6,63)$ \\
\hline$p^{*}$ & 0,753 & 0,870 & 0,792 \\
\hline \multicolumn{4}{|l|}{ Cinsiyet } \\
\hline Kadın & $3,45(0,7-25)$ & 20 (13-99) & $4,98(1,19-7,16)$ \\
\hline Erkek & $4,5(0,87-13)$ & $19,5(7-38)$ & $5,3(4,08-6,63)$ \\
\hline$p^{\star *}$ & 0,142 & 0,080 & 0,039 \\
\hline \multicolumn{4}{|l|}{ Sigara İçimi } \\
\hline Kullanan & $5,15(0,7-25)$ & 20 (13-99) & $5,28(4,08-7,16)$ \\
\hline Kullanmayan & $3,25(0,98-13)$ & $20(7-39)$ & $4,9(1,19-6,63)$ \\
\hline$p^{\star \star}$ & 0,003 & 0,071 & 0,007 \\
\hline
\end{tabular}

*Kruskall Wallis test, **Mann Whitney-U test

Tablo 3. PI, PVI ve EscCO nun demografik veriler ile Spearman'ın sıralama korelasyonu analiz değerlendirmesi

\begin{tabular}{|l|c|c|c|c|c|c|}
\hline \multirow{2}{*}{} & \multicolumn{2}{|c|}{ PI } & \multicolumn{2}{c|}{ PVI } & \multicolumn{2}{c|}{ EscC0 } \\
\cline { 2 - 7 } & $\mathbf{R}$ & $\mathbf{p}$ & $\mathbf{r}$ & $\mathbf{p}$ & $\mathbf{r}$ & $\mathbf{p}$ \\
\hline Boy (cm) & 0,136 & 0,139 & $-0,192$ & $\mathbf{0 , 0 3 5}$ & $-0,059$ & 0,524 \\
\hline Kilo (kg) & $\mathbf{0 , 3 2 0}$ & $<0,001$ & $-\mathbf{0 , 2 1 6}$ & $\mathbf{0 , 0 1 8}$ & $\mathbf{0 , 2 1 9}$ & $\mathbf{0 , 0 1 6}$ \\
\hline Yaş & 0,032 & 0,727 & $-0,255$ & $\mathbf{0 , 0 0 5}$ & $-0,027$ & 0,770 \\
\hline Sp02 (\%) & $-0,386$ & $<0,001$ & $-0,100$ & 0,278 & $-0,090$ & 0,331 \\
\hline $\begin{array}{l}\text { SKB } \\
\text { (mmHg) }\end{array}$ & 0,122 & 0,183 & $-0,150$ & 0,102 & $\mathbf{0 , 2 5 9}$ & $\mathbf{0 , 0 0 4}$ \\
\hline $\begin{array}{l}\text { DKB } \\
\text { (mmHg) }\end{array}$ & 0,178 & 0,051 & $-0,238$ & $\mathbf{0 , 0 0 9}$ & $\mathbf{0 , 3 2 7}$ & $<0,001$ \\
\hline $\begin{array}{l}\text { Kalp Hızl } \\
\text { (Atım/dk) }\end{array}$ & $-0,014$ & 0,878 & $-0,049$ & 0,595 & $\mathbf{0 , 4 7 4}$ & $<0,001$ \\
\hline *Spearman Rho Correlation & & & & \\
\hline
\end{tabular}

PI, PVI ve EscCO değerlerinin demografik parametreler ve yașamsal bulgularla korelasyonu gösterilmiştir. PI ağırlık ile negatif korelasyon gösterir; PVI boy, kilo, yaş ve $D B P$ ile negatif korelasyon gösterir. EscCO ağırlık, SBP, DBP ve kalp hızı ile pozitif korelasyon gösterir.

Çalışmamızda supin, $30^{\circ}$ baş yukarı, $45^{\circ}$ baş yukarı, $20^{\circ}$ trendelenburg, $20^{\circ}$ ters trendelenburg ve pron olmak üzere 6 farklı pozisyon için $\mathrm{PI}, \mathrm{PVI}, \mathrm{EscCO}$ değerleri ölçüldü. En yüksek ortanca $\mathrm{PI}$ değeri Trendelenburg pozisyonunda $(4,55(1,2-13))$ iken, en düşük değer ise pron pozisyonunda $2,95(0,98-8)$ bulundu. En yüksek ortanca PVI değeri $45^{\circ}$ Baş Yukarı (22,5 (13-40)) posizyonunda iken en düşük değer ise pron (19 (11-34)) posizyonunda tespit edildi. EscCO değerinin en yüksek olduğu ortanca değeri prone posizyonunda $(5,34(1,8-6,63))$ iken en düşük ortanca de- ğeri Ters Trendelenburg posizyonunda $(4,92(1,19-6,3))$ olduğu belirlendi. Katııımcıların farklı pozisyondayken ölçülen PI (Şekil 1) , PVI (Şekil 2) ile EscCO (Şekil 3) değerlerinde istatistiksel olarak anlamlı bir fark bulunamadı.(Tablo 2)

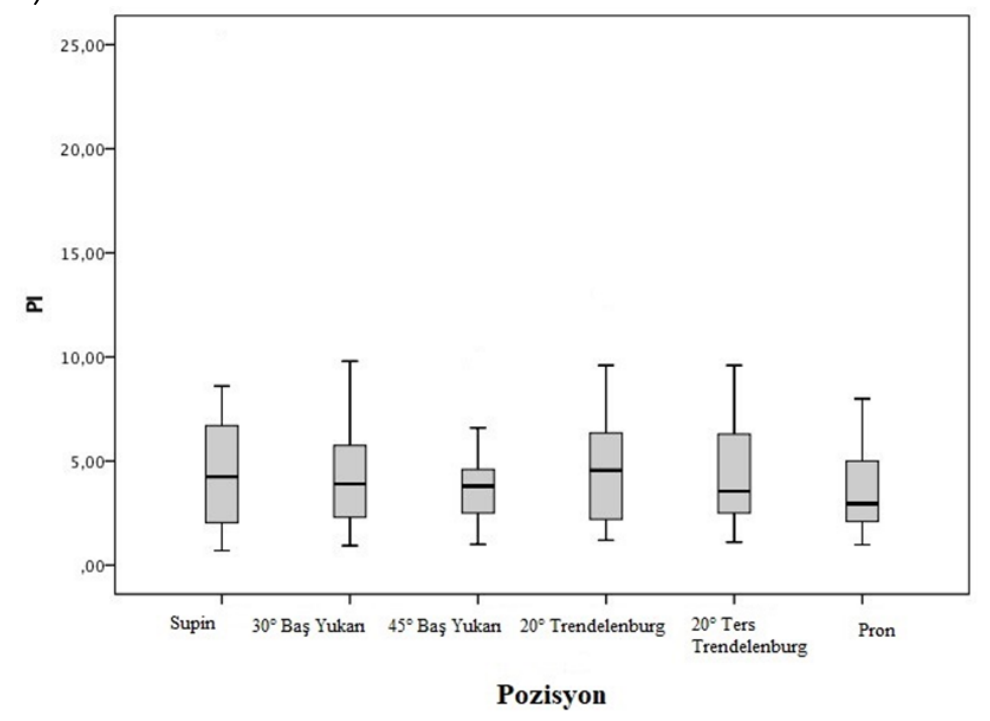

Şekil 1. Perfüzyon İndeksin (PI) Cerrahi pozisyon şekillerine göre değişimleri

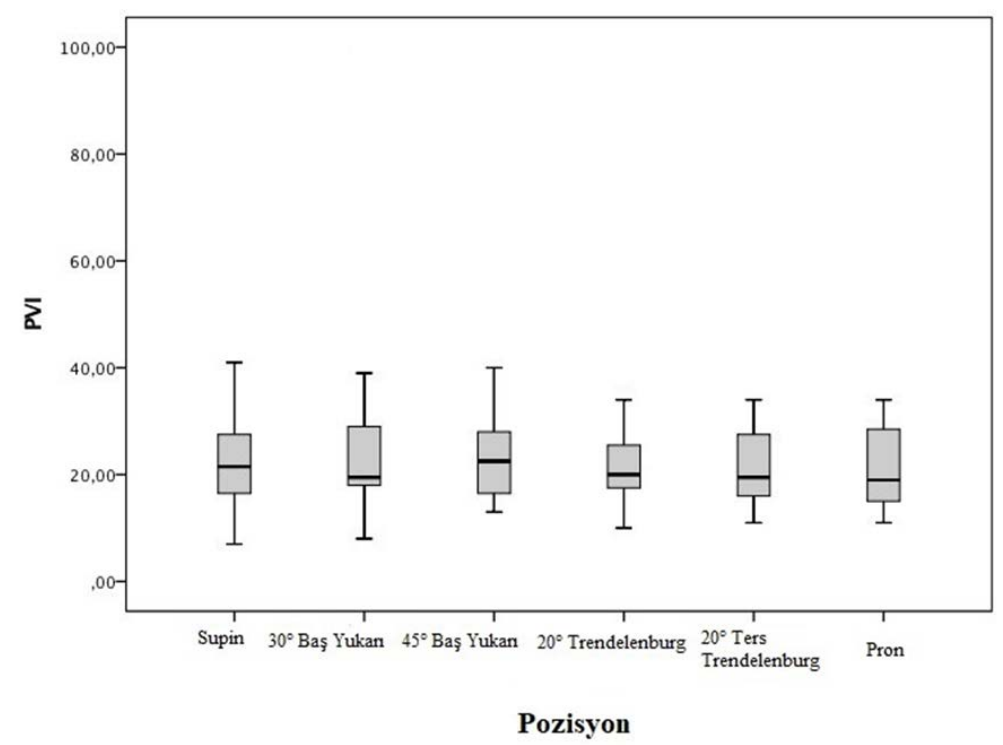

Şekil 2. Pleth değişkenlik indeksinin (PVI) Cerrahi pozisyon şekillerine göre değişimleri

Cinsiyet açısından değerlendirildiğinde EscCO erkeklerde anlamlı olarak yüksek bulundu $(p=0,039)$. Sigara kullananlarda ise EscCO ve PI ölçümleri kullanmayanlara göre anlamlı olarak yüksek bulundu (sırasıyla $p=0,003$, $\mathrm{p}=0,007$ ) (Tablo 2)

$\mathrm{PI}, \mathrm{PVI}, \mathrm{EscCO}$ değerleri ile demografik veriler ve vital bulgular arasında Spearman'ın sıralama korelasyonu yapıldığında ise PI kilo ile negatif korelasyon gösterirken; PVI boy, kilo, yaş ve DBP ile negatif korelasyon gösterimiştir. 
EscCO ise kilo, SBP, DBP ve kalp hızı ile pozitif korelasyon gösterdiği tespit edildi.(Tablo 3)

Lineer regresyon analizi yaptığımızda ise sigara içmenin ve kilonun PI için bağımsız faktörler olduğunu; sigara içmek de PVI için, cinsiyet (EscCO erkeklerde daha yüksektir), boy ve kilonun ise EscCO için bağımsız faktörler ofduğu belirlendi. (Tablo 4)

Tablo 4. PI, PVI ve EscCO nun demografik veriler ile linear regresyon analiz değerlendirmesi

\begin{tabular}{|l|l|l|l|l|l|l|}
\hline & \multicolumn{2}{l}{$\mathbf{P I}$} & \multicolumn{2}{l|}{ PVI } & \multicolumn{2}{l|}{ EscCO } \\
\cline { 2 - 7 } & Odds & $\mathbf{p}$ & $\mathbf{O d d s}$ & $\mathbf{p}$ & Odds & $\mathbf{p}$ \\
\hline (sabit) & $-10,134$ & 0,439 & 63,283 & 0,156 & 25,999 & $<0,001$ \\
\hline Posizyon & $-0,192$ & 0,218 & $-0,755$ & 0,155 & $-0,019$ & 0,665 \\
\hline Sigara Içimi & $-1,680$ & $\mathbf{0 , 0 0 4}$ & $-4,446$ & $\mathbf{0 , 0 2 3}$ & $-0,252$ & 0,120 \\
\hline Cinsiyet & $-1,906$ & 0,237 & 0,011 & 0,998 & 2,767 & $<0,001$ \\
\hline Boy (cm) & 0,104 & 0,275 & $-0,096$ & 0,765 & $-0,158$ & $<0,001$ \\
\hline Kilo (kg) & 0,073 & $\mathbf{0 , 0 0 1}$ & $-0,086$ & 0,261 & 0,021 & $\mathbf{0 , 0 0 1}$ \\
\hline Yaş & $-0,069$ & 0,358 & $-0,322$ & 0,209 & 0,036 & 0,091 \\
\hline *Linear regression analizi & \multicolumn{7}{|l}{} \\
\hline
\end{tabular}

Doğrusal regresyon analizi sigara içmenin ve kilonun PI için bağımsız faktörler olduğunu; sigara içmek de PVI için bağımsız bir faktördür, cinsiyet (EscCO erkeklerde daha yüksektir), boy ve kilo EscCO için bağımsız faktörlerdir.

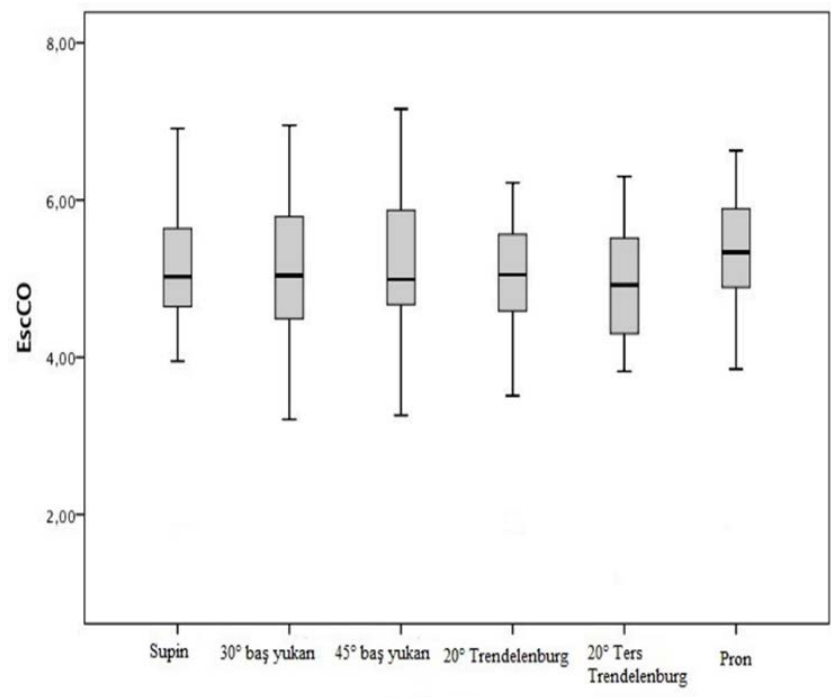

Pozisyon

Şekil 3. Noninvaziv sürekli kardiyak output ölçüm yönteminin (EscCO) Cerrahi pozisyon şekillerine göre değişimleri

\section{Tartışma}

Yaptığımız prospektif gözlemsel çalışmada, sağlıkı bireyler arasındaki PI, PVI ile EscCO değerlerinin cerrahi vücut pozisyonuna göre değişimini incelemiş olup değerlerin pozisyonlara göre anlamlı olarak değişmediğini gösterdik. Bununla birlikte, cerrahi hasta pozisyonları ile SKB, DKB, Kalp Hızı arasında değişim olabileceğini ayrıca bu değerlerin hastanın kilosu ile sigara kullanımından etkilendiğini tespit ettik.
Ameliyathane şartlarında cerrahi öncesi veya cerrahi sırasında hastalara güvenli bir şekilde pozisyon verilmesi ve bu pozisyonlara bağlı oluşabilecek kardiyovasküler ve solunumsal gibi fizyolojik değişikliklerin bilinip gerekli tedbirlerin alınması perioperatif morbiditenin azaltıması adına önemli bir role sahiptir. Hemodinamideki bu değişikliklerin gerektiğinde anestezi derinliğinin ayarlanması, sıvı tedavisi ve farmakolojik müdahalelerle yönetimi gerekli olabilir (1). Cerrahilerde en sık kullanılan pozisyon supin posizyon olup anestezi indüksiyonu için de standart pozisyondur. Dik pozisyondan supin pozisyona geçişte toplanmış venöz kanın alt ekstremitelerden yeniden dağılımı kalbe venöz dönüşü ve ardından kardiyak outputta artış sağlar. Abdominal içeriğin sefale hareketi ile akciğer hacimleri bozulur. Sonuçta fonksiyonel rezidüel kapasitede (FRC) azalma, ventilasyon-perfüzyon uyumsuzluğunda bir artı̧̧ ve pulmoner kompliyansta azalma olur (6). Trendelenburg pozisyondaki pulmoner ve kardiyovasküler değişiklikler genellikle supin pozisyonla ilişkili olanlara benzer, ancak daha aşırıdır. Normotansif hastalarda bu npozisyonda FrankStarling mekanizmasıyla artan venöz dönüş nedeniyle başlangıçta kardiyak outputta geçici bir artış gözlenir. Baroreseptörler aktive olur ve bu durum vazodilatasyon ile kompanse edilir (1). Uzun süren başaşağı pozisyon venöz göllenmeye, baş boyun ve havayolu ödemine neden olur. Kalp rezervleri sınırlı olanlarda artmış venöz dönüş ve sistemik vasküler direnç sorunu akut kalp yetmezliğine neden olur. Bu nedenle Trendelenburg pozisyonlar 20 derece ile sinırlıdır (7).

Ters Trendelenburg pozisyonunda Azalmış venöz dönüşe bağlı hipotansiyona yatkınlık söz konusudur. Faydalı fizyolojik etkiler arasında baş ve boyun venöz drenajında artış, kafa içi basıncında azalma ve pasif yetersizlik olasılığının azalması bulunur. Bu pozisyonun ana komplikasyonları hipotansiyon ve venöz hava embolisi riskidir. Bu pozisyonda supin pozisyona göre FRK ve komplians artar (8). Prone pozisyonuna dönüşte ise yüksek bir karın içi basıncının bağlı olarak inferior vena kaval kompresyonu sonucu azalmış venöz dönüş ve zayıf kalp debisi görülür (9).

Cerrahi sırasında bu tür pozisyonlarda sıvı yanıtını bilmek daha önem arz etmektedir. Bu cevabı öngermek için sürekli kullanılabilir ve yorumlamak için basit özellikte, noninvaziv uygulanabilir, güvenilir nitelikte belirleyicilere intiyaç duyulmaktadır. Bu amaçla noninvaziv, kolay yorumlanabilir ve kullanılabilir bir monitorizasyon yöntemler konusunda son dönem çalışmalar artmış özellikle $\mathrm{PI}, \mathrm{PVI}$ ile EscCO üzerinde yoğunlaşılmıştır $(1,5,10)$.

$\mathrm{PI}$, periferal kapiler yatak içinden ki pulsatil kan akışının pulsatil olmayana oranıdır. PI periferik kan akımındaki değişiklikleri ve periferik perfüzyondaki bozuklukları gösterir. Kolay uygulanabilirliği ve sürekli noninvaziv monitorizasyon sağlaması önemli bir avantajdır. Non invaziv, parmağa/kulağa takılan oksimetre probu ile çalışır. PI periferik mikrosirkülasyondaki değişikliklerle ilgili olup, bu damar 
durumu, sempatik reaksiyonlar ve dolaşım sisteminin fonksiyonu ile ilişkilidir (11). Periferik perfüzyon kardiyak output (CO) ve periferik vazomotor tondan etkilenir ve sempatik vazokonstriksiyona ve cilt sıcaklığına duyarlıdır. Sempatik ton ve cilt sıcakıı̆ı sabit tutulursa PI CO'nun bir vekili olarak kullanılabilir (12). Pl in cerrahi pozisyonlardaki etkilerini inceleyen güncel bir çalışmada katılımcıların $\mathrm{PI}$ değerleri farklı vücut pozisyonlarından etkilendiği, oturma pozisyonunda (4.5 \pm 2.5$)$ en düşük, Trendelenburg pozisyonunda ise $(7.8 \pm 3.8)$ bireylerde en yüksek değeri aldığı gösterilmiş (1). Bizim çalışmamızda ise en düşük değer 2,95 ortanca değeri ile pron pozisyonunda en yüksek değer ise 4,55 ortanca değeri ile önceki çalışmaya benzer şekilde Trendelenburg pozisyonunda olmuştur ancak istatiksel olarak anlamlı değildi. Bunun nedenini ölçümler arası ölçüm sürelerine bağlamaktayız. Önceki çalışmada bu süre toplamda $7 \mathrm{dk}$ iken bizim çalışmamızda $10 \mathrm{dk}$ dır. Bir diğer çalışmada ise $45^{\circ}$ baş yukarıda takip edilen gönüllü katılımcılarda hastanın pozisyonunu supin hale getirip pasif bacak kaldırma testi yapılıyor. PI değeri başlangıç değere göre anlamlı derece artıyor. Hasta tekrar başlangıç pozisyonuna gelince PI tekrardan anlamlı derecede düşüyor (4). Bizim çalışmamızda ise supin pozisyonunda ortanca değerimiz 4,25 iken $45^{\circ}$ baş yukarıda 3,8 olarak düşüş göstermiştir. Pasif bacak kaldırma pozisyonuna en yakın pozisyonumuz $20^{\circ}$ Trendelenburg pozisyonu olup 4,55 değerini ölçtük. Çalışmamız Maughan ve ark. Yaptıkları çalışmaya paralellik göstermektedir. Ancak bu ölçümler arasında anlamlı fark bulamadık. Bu çalışmada ki iki pozisyon arasındaki toplam süre $8 \mathrm{dk}$ iken iken bizim çalışmamızda $10 \mathrm{dk}$. Sürenin uzunluğunun kompanzasyon sürecine destek verip değerlerin daha stabil olarak seyrettiğine inanmaktayı.

$\mathrm{PVI}$ ise perfüzyon indeksi baz alarak puls oksimetre sinyallerinin solunum siklusu ile gösterdiği değişimin hesaplanması esasına dayanır. PVI= (PI max- PI min)/ PI max $\mathrm{x}$ 1000 formülü ile hesaplanır. Her iki parametre periferik vasküler tonundaki değişikliklerden periferik perfüzyon dinamiklerini değerlendirmek için kullanıımıştır. Her iki parametre de hastaların sıvı cevabının, non-invaziv, otomatik ve sürekli ölçen bir monitörizasyon şeklidir. PVI>14 \%81 sensitivite ile sIVı yanıtına pozitif cevabı öngörür (4). PVI'nın mekanik olarak ventile edilen hastalarda sıvı duyarılığını öngörme konusundaki makul yeteneği zaten kanitlanmıştır (13).

Ancak spontan solunumu olan hastalarda dinamik indeksleri değerlendirmek daha karmaşıktır. Sezaryen ile doğum yapan hastalarda PVI'nın spinal anestezi sonrası hipotansiyonu öngörmedeki etkisi belirtilmiş olsa da, PVI \% 19'un üzerindeki değerlerin, spontan solunumu olan hastalarda pasif baca kaldırmaya yanıı zayıf fakat anlamlı olduğunu gösterilmişse de, her nefeste tidal hacmini standartlaştırmak mümkün olmadığından, PVI gibi kalp-akciğer etkile- şimlerine dayanan dinamik ölçümlerin güvenilirliği sorgulanabilir $(10,14,15)$. PVI nın spontan soluyan katılımcılarda cerrahi pozisyonlardaki değişimlerini inceleyen bir çalışmada 45 derece pozisyondan pasif bacak kaldırma yapıldığında PVI nın anlamlı olarak düştüğünü, yarı oturur pozisyonuna geçişte ise anlamlı olarak yükseldiği belirtilmiş (10). Bunun aksine başka bir benzer çalışma da ise supin pozisyondan pasif bacak kaldırma yapılan grup ile supin pozisyonundan Trendelenburg pozisyonuna geçilen gruplarda PVI değerlerinin yükseldiği tespit edilmiş. Bu artışların, vasküler tonusta bir değişikliğe neden olabilecek her iki pozisyonun vagal etkisinden kaynaklanıyor olabileceği belirtilmiş (16). Bizim çalışmamızda ise tüm pozisyonlardaki sonuçlar birbirine yakın bulundu. Diğer çalışmalardan farklı olarak çalışmamızda iki pozisyon arasındaki süre uzun olup 10 dakikadır. Pasif bacak kaldırma yöntemi uygulanmadığından ani değişiklikler gözlenmemiştir.

EscCO EKG ve periferik nabız dalgasının her vurumunda nabız oksimetresi ve EKG-sinyalleriyle elde edilen Nabız Dalga Geçiş Süresini (PWTT) kullanarak kardiyak outputu belirleyen yeni bir teknolojidir. EKG ve SpO2 parametrelerini kullanarak gerçek zamanlı, sürekli ve non-invaziv kardiyak çıktı sağlar (5). lyi bir hemodinamik izleme sistemi, ilgili değişkenlerin doğru ve tekrarlanabilir ölçümlerini sağlamalı, yorumlanabilir veriler sağlamalı, kullanımı kolay, hazır ve operatörden bağımsız olmalı, hızı bir yanıt süresine sahip olmalı, zarar vermemeli, uygun maliyetli olmamalı ve Terapiyi yönlendirmek için kullanılabilir. EsCCO tekniği bu kriterlerin çoğunu karşllıyor gibi görünmesine rağmen, literatür verilerinin azlığı kesin sonuçlara varılmasını engelliyor (17). Güncel ve az sayıda literatür bilgilerinde intraoperatif hemodinamik monitörizasyon açısından diğer invazif yöntemlere göre zayıf bir izlem aracı olarak belirtilse de postoperatif izlem açısından daha uyumlu olduğu tespit edilmiştir $(18,19)$. Ancak cerrahi pozisyonlardaki EscCO değişimi ile ilgili herhangi bir bilgi bulunmamaktadır. Yaptığımız çalışmada prone pozisyonunda en yüksek değere ulaşılmışken en az değer $20^{\circ}$ Ters Trendelenburg pozisyonunda görülmüştür. Ancak tüm pozisyonlardaki değerler arasında anlamlı bir fark tespit edemedik. Çalışmamızın bazı sınırlamaları vardır. İlk olarak, çalışmaya katılanlar sadece genç ve sağlıklı hastalardan oluşuyordu. Dolayısıyla, sonuçlar tüm hastalar için genelleştirilemez. İkinci olarak hastalar cihazın uygulanabilirliğini sınırlayabilen düzenli kardiyak ritime sahip olmalıdır. Sıvı duyarlılı̆ı̆ın diğer dinamik göstergelerinde olduğu gibi, $\mathrm{PI}, \mathrm{PVI}$ ve EsCCO kardiyak aritmili hastalarda kullanılamaz. Son olarak da çalışmamızda sistemik vasküler direnci değerlendirmedik. sonuçlarımız, vazoaktif ilaç alan hastalar gibi sistemik vasküler dirençlerin farklı olduğu durumlarla karşılaştırılamaz.

Sonuç olarak bu çalışma, PI, PVI ile EscCO nun tüm cerrahi pozisyonlarda herhangi bir değişikliğe uğramadığını ve her üç parametrenin de spontan solunumuna sahip 
genç sağlıklı bireylerde pozisyondan etkilenmediği ortaya koymuştur. Her üç parametrenin en yüksek ve en düşük değerleri farklı pozisyonlarda farklı olsa da genel olarak birbirlerine paralel parametreler olabileceğini gördük. YaptığımIz çalışma ile $\mathrm{PI}, \mathrm{PVI}$ ve EscCO nun spontan solunumuna sahip non-invaziv hemodinamik monitörizasyonu takibi anlayışımıza katkıda bulunmaktadır.

Etik Onam: Çalışma için Harran Üniversitesi Tıp Fakültesi Etik Kurulu'ndan etik kurul onayı alındı (2020 yılı,05 oturum, 30 sayilı).

\section{Kaynaklar}

1.Tapar H, Karaman S, Dogru S, Karaman T, Sahin A, Tapar GG et al. The effect of patient positions on perfusion index. BMC Anesthesiol. 2018;18(1):111

2. Kim DH, Shin S, Kim JY, Kim SH, Jo M, Choi YS. Pulse pressure variation and pleth variability index as predictors of fluid responsiveness in patients undergoing spinal surgery in the prone position. Ther Clin Risk Manag. 2018 ;14:1175-83.

3. Coeckelenbergh S, Delaporte A, Ghoundiwal D, Bidgoli J, Fils JF, Schmartz $D$ et al. Pleth variability index versus pulse pressure variation for intraoperative goal-directed fluid therapy in patients undergoing lowto-moderate risk abdominal surgery: a randomized controlled trial. BMC Anesthesiol. 2019;19(1):34

4. Maughan BC, Seigel TA, Napoli AM. Pleth variability index and fluid responsiveness of hemodynamically stable patients after cardiothoracic surgery. Am J Crit Care. 2015;24(2):172-5.

5. Dache S, Van Rompaey N, Joosten A, Desebbe O, Saxena S, Eynden FV et al. Comparison of the ability of esCCO and Volume View to measure trends in cardiac output in patients undergoing cardiac surgery. Anaesthesiol Intensive Ther. 2017;49(3):175-80

6. David JW Knight, MRCP FRCA, Ravi P Mahajan, DM FRCA. Patient positioning in anaesthesia. Continuing Education in Anaesthesia Critical Care \& Pain. 2004;5(4):160-63

7. Nakajima $Y$, Mizobe T, Matsukawa T. Thermoregulatory response to intraoperative head-down tilt. Anesth analg. 2002;94(1):221-6

8. Summers RL, Thompson JR, Hoodward LH, Martin DS. Physiologic mechanisms associated with the Trendelenburg Position Am J Clin Med. 2009;(6):24-7

9. Edgcombe H., Carter K., Yarrow S. Anaesthesia in the prone position. BJA. 2008; 100 (2): 165-83

10. Keller G, Cassar E, Desebbe O, Lehot JJ, Cannesson M. Ability of pleth variability index to detect hemodynamic changes induced by passive leg raising in spontaneously breathing volunteers. Crit Care. 2008;12(2):R37

11. Huang HS, Chu CL, Tsai CT, Wu CK, Lai LP, Yeh HM. Perfusion index derived from a pulse oximeter can detect changes in peripheral microcirculation during uretero-renal-scopy stone manipulation (URSSM). PLoS One. $2014 ; 9(12):$ e115743

12. Godai K, Matsunaga A, Kanmura Y. The effects of hemodynamic management using the trend of the perfusion index and pulse pressure variation on tissue perfusion: a randomized pilot study. JA Clin Rep. $2019 ; 5(1): 72$.

13. Chu $H$, Wang $Y$, Sun $Y$, Wang $G$. Accuracy of pleth variability index to predict fluid responsiveness in mechanically ventilated patients: a systematic review and metaanalysis. J Clin Monit Comput 2016;30(3):265-74

14. Sun S, Huang SQ. Role of pleth variability index for predicting hypotension after spinal anesthesia for cesarean section. Int J Obstet Anesth 2014; 23: 324-9

15. De Backer D, Pinsky MR. Can one predict fluid responsiveness in spontaneously breathing patients? Intensive Care Med 2007;33:1111-

\section{3}

16. Demirci OL, Çıkrıkçı Işık G, Çorbacıoğlu ŞK, Çevik Y. Comparing Pleth variability index (PVI) variation induced by passive leg raising and Trendelenburg position in healthy volunteers. Am J Emerg Med. 2019 May 7. doi: 10.1016/j.ajem.2019.05.015. [Epub ahead of print] 17. Vincent JL, Rhodes A, Perel A, Martin GS, Della Rocca G, Vallet B, et al. Clinical review: Update on hemodynamic monitoring - a consensus of 16. Crit Care. 2011;15(4):229

18. Suzuki T, Suzuki Y, Okuda J, Minoshima R, Misonoo Y, Ueda T, et al. Cardiac output and stroke volume variation measured by the pulse wave transit time method: a comparison with an arterial pressure-based cardiac output system. J Clin Monit Comput. 2019;33(3):385-92.

19. Terada T, Oiwa A, Maemura Y, Robert S, Kessoku S, Ochiai R. Comparison of the ability of two continuous cardiac output monitors to measure trends in cardiac output: estimated continuous cardiac output measured by modified pulse wave transit time and an arterial pulse contour-based cardiac output device. J Clin Monit Comput. 2016 ;30(5):6217 